\title{
Measuring patients' satisfaction with their anti-TNF treatment in severe Crohn's disease: scoring and psychometric validation of the Satisfaction for PAtients in Crohn's diseasE Questionnaire (SPACE-Q ${ }^{\odot}$ )
}

This article was published in the following Dove Press journal:

Patient Preference and Adherence

4 December 2014

Number of times this article has been viewed

\section{Hélène Gilet' \\ Benoit Arnould' \\ Fatoumata Fofana' \\ Pierre Clerson ${ }^{2}$ \\ Jean-Frédéric Colombel ${ }^{10}$ \\ Olivier D'Hondt ${ }^{2}$ \\ Patrick Faure 4 \\ Hervé Hagège ${ }^{5}$ \\ Maria Nachury ${ }^{3}$ \\ Stéphane Nahon ${ }^{6}$ \\ Gilbert Tucat ${ }^{7}$ \\ Luc Vandromme ${ }^{8}$ \\ Ines Cazala-Telinge ${ }^{9}$ \\ Emmanuel Thibout ${ }^{9}$ \\ 'HEOR and Strategic Market Access, Mapi, Lyon, France; ${ }^{2}$ Orgamétrie, Roubaix, France; ${ }^{3}$ Hôpital Claude Huriez, Lille, France; ${ }^{4} \mathrm{Clinique}$ Saint-Jean du Languedoc, Toulouse, France; ${ }^{5}$ Centre Hospitalier Intercommunal, Créteil, France; ${ }^{6}$ Centre Hospitalier Intercommunal, Le Raincy Montfermeil, France; ${ }^{7}$ Gastroenterologist, Private Clinical Practice, Paris, France; ${ }^{8}$ Gastroenterologist, Private Clinical Practice, Reims, France; ${ }^{9}$ Abbvie France, Rungis, France; ${ }^{10} \mathrm{Icahn}$ School of Medicine at Mount Sinai, New York, NY, USA}

Correspondence: Benoit Arnould

27, Rue de la Villette, 69003 Lyon, France

Tel +33472 I366 62

Fax +33472 I3 5I 40

Email barnould@mapigroup.com
Background: Severe Crohn's disease management includes anti-tumor necrosis factor (anti-TNF) drugs that differ from early-stage treatments regarding efficacy, safety, and convenience. This study aimed to finalize and psychometrically validate the Satisfaction for PAtients in Crohn's diseasE Questionnaire (SPACE-Q ${ }^{\circ}$ ), developed to measure satisfaction with anti-TNF treatment in patients with severe Crohn's disease.

Methods: A total of 279 patients with severe Crohn's disease receiving anti-TNF therapy completed the SPACE-Q 62-item pilot version at inclusion and 12 and 13 weeks after first anti-TNF injection. The final SPACE-Q scoring was defined using multitrait and regression analyses and clinical relevance considerations. Psychometric validation included clinical validity against Harvey-Bradshaw score, concurrent validity against Treatment Satisfaction Questionnaire for Medication (TSQM), internal consistency reliability, test-retest reliability, and responsiveness against the patient global impression of change (PGIC).

Results: Quality of completion was good (55\%-67\% of patients completed all items). Four items were removed from the questionnaire. Eleven scores were defined within the final 58-item SPACE-Q: disease control; symptoms, anal symptoms, and quality of life transition scales; tolerability; convenience; expectation confirmation toward efficacy, side effects, and convenience; satisfaction with treatment; and motivation. Scores met standards for concurrent validity (correlation between SPACE-Q satisfaction with treatment and TSQM satisfaction scores $=0.59$ ), internal consistency reliability (Cronbach's $\alpha=0.67-0.93)$, test-retest reliability (intraclass correlations $=0.62-0.91$ ), and responsiveness (improvement in treatment experience assessed by the SPACE-Q for patients reporting improvement on the PGIC). Significantly different mean scores were observed between groups of patients with different Harvey-Bradshaw disease severity scores.

Conclusion: The SPACE-Q is a valid, reliable, and responsive instrument to measure satisfaction with anti-TNF treatment in patients with severe Crohn's disease and for use in future studies.

Keywords: Crohn's disease, satisfaction, anti-TNF treatment, questionnaire

\section{Introduction}

Crohn's disease is a chronic inflammatory disease of the gastrointestinal tract. It causes symptoms such as diarrhea, abdominal pain, fever, loss of appetite, subsequent weight loss, and, in the most severe cases, complications such as obstructions and abscesses. ${ }^{1}$ 
The early onset of the disease, its morbidity, its symptoms, and the disease's required lifelong management regimen profoundly affect patients' lives. ${ }^{2,3}$ There are no curative treatments available today. The drugs used to manage Crohn's disease symptoms include aminosalicylates, corticosteroids, immune modifiers, antibiotics, and anti-tumor necrosis factor (TNF). Treatment guidelines recommend using a step-up strategy; as the disease becomes more severe, more efficient but more potentially toxic drugs are used. ${ }^{4}$ Anti-TNF drugs, including infliximab and adalimumab, are usually indicated in moderate to severe active Crohn's disease when patients experience relapses and long disease duration and the condition can become refractory to other conventional medical treatments. ${ }^{4}$ In the maintenance phase, anti-TNF treatments require the patient either to visit the hospital 1 day every 8 weeks to receive intravenous injections of infliximab or to perform subcutaneous selfinjections of adalimumab every 2 weeks. Patient satisfaction with treatment, especially with anti-TNF drugs, may be influenced by the treatment delivery mode, frequency of administration, associated side effects, and, consequently, impact on the patient's quality of life. ${ }^{5}$

Patient satisfaction is a subjective experience; it can be defined as the emotive feeling resulting from the comparison between the actual perceived performance and quality of the treatment with the original expectations. ${ }^{6,7}$ A review by Dias Barbosa et $\mathrm{al}^{8}$ found that in a wide variety of diseases and study settings, patients' satisfaction with treatment was positively associated with treatment compliance, persistence, and adherence. Thus, measuring satisfaction is useful for patient management and understanding at the individual level to inform treatment decisions.

Several tools are already available to evaluate patient treatment satisfaction. These include both generic questionnaires such as the Treatment Satisfaction Questionnaire for Medication (TSQM) ${ }^{9}$ and the Treatment Satisfaction with Medicines Questionnaire (SATMED-Q) ${ }^{10}$ and a Crohn's disease-specific questionnaire, the Treatment Satisfaction Questionnaire for Crohn's Disease (TSQ-C). ${ }^{11}$ However, none of these instruments is appropriate to assess patient satisfaction with respect to the specificities of anti-TNF treatments in severe Crohn's disease (eg, delivery mode, frequency of administration). ${ }^{12}$ To address this issue, the Satisfaction for PAtients in Crohn's diseasE Questionnaire $\left(\mathrm{SPACE}-\mathrm{Q}^{\odot}\right.$ ) was recently developed. ${ }^{13}$

The objective of this multicenter, longitudinal, observational study was to develop a scoring method for the
SPACE-Q and to evaluate its psychometric properties in order to ensure that it is a valid and appropriate instrument for use in future clinical trials or epidemiological studies.

\section{Materials and methods SPACE-Q}

The SPACE-Q was initially developed in French using stateof-the-art methodology. ${ }^{14}$ The multistep development process is reported in a previous manuscript. ${ }^{13}$ Briefly, a literature review was performed to identify existing questionnaires and concepts of interest. Then, exploratory interviews were conducted in France with patients with severe Crohn's disease to create the conceptual model of the questionnaire and generate the items. Finally, comprehension test interviews with Crohn's disease patients were performed to inform final modifications to the instrument. A clinician advisory board was involved throughout the development process to provide clinical expertise and identify key issues as decisions were made about the items of the questionnaire.

The pilot version comprised 62 items. ${ }^{15}$ Based on the results of the literature review and on the conceptual model generated during the questionnaire development phase, 60 items of the SPACE-Q were grouped in an initial hypothetical structure that included four sections: treatment benefits, tolerability, convenience, and treatment satisfaction. The two remaining items, which included a question on the type of treatment administration and an open-ended question addressing patient expectations about future new treatments, were not integrated into the scoring structure. The 19 items within the treatment benefits section were divided into three dimensions: disease control (eight items about treatmentrelated patient well-being, health state, protection), symptoms transition scale (ten items about symptom improvement with the current treatment compared with previous treatment), and expectation confirmation toward treatment efficacy (one item). The tolerability section was composed of two dimensions: tolerability (five items about treatment-related side effects information, worries, bother) and acceptance of side effects (one item). The convenience section was composed of two dimensions: convenience (14 items about mode of administration-related constraints, organizational constraints) and acceptance of constraints (one item). The 20 items within the treatment satisfaction section were grouped into three dimensions: quality of life transition scale (eight items about treatment-related changes in health-related quality of life domains, including social life, family life, and physical aspects), satisfaction with treatment (ten items about 
satisfaction with efficacy against the symptoms and with the impact on quality of life), and intents (two items about motivation to continue taking treatment and likelihood of recommending their treatment to other patients).

Most response choices were formatted on four- or fivepoint Likert scales (eg, false/mostly false/mostly true/true; very negative/mostly negative/neither negative nor positive/ mostly positive/very positive). Only the response choices for the six items about mode of administration-related constraints were formatted as yes/no.

\section{Patients and study design}

This multicenter, longitudinal, observational study was conducted with gastroenterologists who recruited patients who had been diagnosed with severe and active Crohn's disease according to the physician's opinion and for whom an antiTNF treatment had been indicated. Patients enrolled in the study were either patients who at inclusion were switched to a new anti-TNF treatment by the clinician or those who did not respond to conventional therapy with corticosteroids and/or immunosuppressors and were thus prescribed an antiTNF treatment.

Information about patients' sociodemographic, clinical, and treatment characteristics was collected at inclusion and week 12. At week 12, physicians were also asked to evaluate the therapeutic efficacy of the treatment on a four-point scale ranging from "null or deterioration" to "high".

A pen and paper version of the SPACE-Q was selfcompleted by patients at inclusion before they received their first anti-TNF injection. The questionnaire was also selfcompleted by the patients at week 12 to evaluate its responsiveness and at week 13 to assess its test-retest reliability.

A seven-point patient global impression of change (PGIC) scale was self-completed by patients at week 12 and week 13 . Patients were also asked to complete the TSQM, a selfadministered questionnaire assessing patients' satisfaction with medication, at inclusion and week 12 . The TSQM is a generic questionnaire that contains eleven items measuring effectiveness, side effects, convenience, and global satisfaction. ${ }^{9}$ Scores range from 0 to 100 , with higher scores indicating greater satisfaction.

The study protocol was submitted to the Comité d'Ethique de Recherche (CER) du Comité de Protection des Personnes d'Ile de France IV (Hôpital St Louis, Paris, France). The study was conducted in compliance with the ethical principles derived from the Declaration of Helsinki; an informed consent was signed by all patients included in the study.

\section{Statistical analysis}

\section{Analysis sample}

The analysis sample was composed of patients within the study population who met the selection criteria and had completed at least one item of the SPACE-Q.

\section{Finalization phase}

To confirm the hypothesized structure of the questionnaire, potentially improve it, and define the scoring rules, the quality of completion of the SPACE-Q and the distribution of item responses were first investigated. The questionnaire was composed of both psychometric and composite dimensions. A psychometric dimension is composed of items correlated with each other and measuring a single similar concept; in the SPACE-Q, psychometric dimensions were those about treatment benefits and treatment satisfaction. A composite dimension is composed of items that are a combination of indicators of a common concept but not necessarily correlated with each other; in the SPACE-Q, composite dimensions were those about tolerability and convenience. Due to the presence of these different types of dimensions, the statistical methods were adapted to the differing natures of the concepts measured. Multitrait analysis was used to confirm the hypothesized structure for psychometric scores; item convergent validity (correlation of each item with its hypothesized dimension $\geq 0.40$ ) and item discriminant validity (correlation of each item with its hypothesized dimension superior to the correlation of the same item with other dimensions) were assessed. ${ }^{16}$ Linear regression was used to confirm the hypothesized structure for composite scores. Clinical relevance was also considered throughout the finalization process.

\section{Psychometric validation phase}

The psychometric properties of the SPACE-Q scores, including validity, reliability, and responsiveness, were evaluated. Validity is the degree to which the instrument measures what it is supposed to measure. The clinical validity (the extent to which the instrument is able to distinguish clinically different groups ${ }^{17}$ was assessed by comparing SPACE-Q scores with the degree of disease severity as measured by the Harvey-Bradshaw index (score $<4$ : inactive disease; score between 4 and 12: active disease; score $>12$ : very severe disease). ${ }^{18}$ The instrument's concurrent validity (the extent to which the scores correlate with scores from other patient-reported outcome instruments measuring similar concepts) was evaluated by calculating Pearson correlation 
coefficients between SPACE-Q and TSQM scores. A newly developed questionnaire is generally expected to be moderately correlated $(\approx 0.40-0.70)$ with an existing questionnaire measuring similar concepts. If the correlation is close to 1 , the new questionnaire is considered to be redundant with the existing measure. ${ }^{17}$

Reliability is the degree to which the instrument is free from measurement error. The internal consistency reliability (the extent to which items within a dimension are consistent with each other and measure a single underlying concept) was evaluated using Cronbach's $\alpha$, with a value $\geq 0.70$ considered satisfactory. ${ }^{19}$ Test-retest reliability (the extent to which the questionnaire yields the same scores each time it is administered, all other things being stable) was also evaluated. Intraclass correlation coefficients were calculated between week 12 and week 13 administrations for patients considered stable as reported by both the physician and the patient. The test-retest reliability was considered good if coefficients were $>0.70 .{ }^{19}$ Internal consistency reliability was not assessed for composite scores because, by nature, these scores include items covering heterogeneous aspects. ${ }^{20}$

Responsiveness (the ability of the questionnaire to detect changes over time $)^{21}$ was evaluated by comparing changes in SPACE-Q scores according to patient responses to the sevenpoint PGIC scale and to the change in Harvey-Bradshaw score from inclusion to week 12. For PGIC comparison, patients who reported "no change" or "minimally improved" or "minimally worsened" were grouped together and considered as patients with no change, while patients who reported much or very much improvement were grouped together as patients with improvement. As only three patients reported much or very much worsening on the PGIC, these patients were excluded from the responsiveness analysis due to the small sample size. Effect sizes were also computed within the improved and no change groups by dividing the difference between the mean scores at week 12 and at inclusion by the standard deviation at inclusion; effect sizes around 0.20, 0.50, and 0.80 indicate small, moderate, and large changes, respectively. ${ }^{22}$

\section{Statistical tests, level of significance, and software}

$t$-Tests were used when comparing two groups of patients, analysis of variance when comparing three groups of patients or more, and paired $t$-tests when comparing a change against 0 . As the emphasis in psychometric analysis is on evaluating the magnitude of relationships between variables and the overall pattern of results rather than significance testing, no adjustments were used for multiplicity of tests. When necessary, the threshold for statistical significance was fixed at 5\%. The statistical analysis was performed using SAS software for Windows (Version 9.2, SAS Institute Inc., Cary, NC, USA).

\section{Results Study population}

There were 301 patients recruited by 32 physicians from March 2010 to July 2011. Seven patients who did not meet all the inclusion criteria and 15 who did not complete the SPACE-Q at any of the visits were excluded from the analysis. The remaining 279 patients were included in the analysis sample. Patients' characteristics at inclusion are presented in Table 1 . Mean age was 36 years and 56\% were female. The majority of the patients $(79 \%)$ had been diagnosed with Crohn's disease between the ages of 17 and 40 years. From the time of inclusion to week $12,65 \%$ of the patients reported an improvement according to PGIC and 59\% had high therapeutic efficacy reported by physicians (Table 2). Only three patients reported that their condition had deteriorated at week 12 compared with inclusion.

\section{Finalization phase}

The overall quality of completion of the SPACE-Q was good. At inclusion, $90 \%$ of the recruited patients completed

Table I Characteristics of patients at inclusion

\begin{tabular}{ll}
\hline Variable & Analysis sample (N=279) \\
\hline Age (years) & $278(\mathrm{I})$ \\
$\mathrm{N}$ (missing) & $35.8(12.4)$ \\
Mean (SD) & $18.3-88.7$ \\
Min-max & $56 \%$ \\
Sex - female & \\
Tobacco consumption & $276(3)$ \\
N (missing) & $34 \%$ \\
Current smoker & $65 \%$ \\
Stopped smoking or never smoked & \\
Age at diagnosis & $11 \%$ \\
$\leq 16$ years & $79 \%$ \\
I7-40 years & $10 \%$ \\
$>40$ years & \\
Site of Crohn's disease & \\
Ileal & $31 \%$ \\
Colonic & $19 \%$ \\
Ileocolonic & $47 \%$ \\
Upper gastrointestinal tract & $11 \%$ \\
Harvey-Bradshaw total score & \\
N (missing) & $268(10)$ \\
Mean (SD) & $7.1(4.7)$ \\
Min-max & $0.0-23.0$ \\
\hline
\end{tabular}

Notes: a Upper gastrointestinal tract can be added to ileal, colonic, and ileocolonic when concomitant upper gastrointestinal disease is present. 'Score $<4$ : inactive disease; score $>4$ and $<12$ : active disease; score $>12$ : very severe disease. Abbreviation: SD, standard deviation. 
Table 2 Characteristics of patients at week 12

\begin{tabular}{ll}
\hline Variable & Analysis sample (N=279) \\
\hline Harvey-Bradshaw total score & \\
N (missing) & $264(15)$ \\
Mean (SD) & $3.5(5.0)$ \\
Min-max & $0.0-55.0$ \\
Therapeutic efficacy evaluated by physician & \\
High & $59 \%$ \\
Moderate & $24 \%$ \\
Minimal & $7 \%$ \\
Null or deterioration & $6 \%$ \\
Patient global impression of change & \\
Very much improved & $10 \%$ \\
Much improved & $31 \%$ \\
Minimally improved & $24 \%$ \\
No change & $14 \%$ \\
Minimally worsened & $3 \%$ \\
Much worsened & $1 \%$ \\
Very much worsened & $<1 \%$ \\
Treatments received since inclusion & \\
At least one corticosteroid & $38 \%$ \\
At least one immunosuppressant & $41 \%$ \\
Anti-TNF: infliximab & $31 \%$ \\
Anti-TNF: adalimumab & $66 \%$ \\
\hline
\end{tabular}

Notes: ${ }^{\text {SScore }}<4$ : inactive disease; score $>4$ and $<12$ : active disease; score $>12$ : very severe disease.

Abbreviations: SD, standard deviation; TNF, tumor necrosis factor.

the questionnaire with a mean number of missing items of four out of 62. Fifty-five percent of the patients completed all items. Eight of 62 items had $>10 \%$ missing data but $<20 \%$; this included five items about the mode of administrationrelated constraints $(14.4 \%-15.9 \%$ missing data $)$, the two items about rapidity and efficacy of relief $(11.4 \%-12.2 \%$ missing data, respectively), and the item about satisfaction with effect on professional life ( $10.7 \%$ missing data). Eightynine percent of the patients completed the questionnaire at week 12 and $78 \%$ at week 13 . Compared with the inclusion visit, better results were observed regarding the number of missing items; $69 \%$ of the patients completed all items at week 12 and $67 \%$ at week 13 . No item had $>10 \%$ missing data at week 12 and week 13 visits.

The response distribution was good for all items. No response choice was used by $>50 \%$ of the patients. No floor or ceiling effects and no bimodal distributions were observed, supporting the relevance of all response choices and item eligibility for aggregation into scores.

Only minor modifications were made to the hypothetical structure of the questionnaire. These modifications, as well as the final structure, are described here.

Within the disease control and symptoms transition scale dimensions, most items met the item convergent and discriminant validity criteria. Only three items were weakly correlated with their dimensions: items about anal pain $(r=0.38)$, anal leakage $(r=0.23)$, and food problems $(r=0.08)$. As anal symptoms do not affect all patients but are of major importance from a clinical perspective, the clinicians of the advisory board recommended keeping the two anal symptomrelated items in the final questionnaire and creating a new dimension called anal symptom transition scale. The item about food problems was removed from the questionnaire.

Within the tolerability dimension, the item about women's willingness to have a child was removed from the questionnaire. Even though the item was considered very interesting by the clinicians of the advisory board, this item is relevant only to a small subgroup of patients, and its inclusion into an aggregated score was problematic. In addition, women tended to give the same response to this item and to the item measuring concerns about health. It was therefore determined that removing this item would not result in loss of information.

Within the convenience dimension, three items did not have a statistically significant impact on acceptance of convenience. The two items about treatment-related organizational constraints on timing and scheduled appointments were removed from the questionnaire, as they were not considered of major clinical importance in the overall evaluation of treatment convenience. The item evaluating constraints related to expenses, though less relevant in the French context because of the French health insurance system, was retained in the convenience dimension, as it is potentially relevant in other countries.

A final change was made based on conceptual considerations. The items about acceptance of side effects and acceptance of constraints, which are closely related to patients' motivation, were grouped together with the items of the intents dimension. The resulting dimension was named motivation dimension.

Ultimately, the final scoring structure of the questionnaire was based upon six psychometric dimension scores, two composite dimension scores, and three single-item scores (Table 3). The question about the type of treatment administration and the open-ended question addressing patient expectations about future new treatments remained unchanged and were kept outside the scoring structure. The final questionnaire contained 58 items. A score was obtained for each dimension by calculating either the sum of items for the composite dimensions or the mean of items followed by a linear transformation to a $0-100$ scale for the psychometric dimensions. Linear transformation was also performed for the single-item dimensions. For all dimensions, the higher the 
Table 3 Final scoring structure of the Satisfaction for PAtients in Crohn's diseasE Questionnaire to assess patients' satisfaction with anti-tumor necrosis factor treatment ${ }^{\mathrm{a}}$

\begin{tabular}{|c|c|c|c|c|}
\hline Dimension score & Type of score & $\begin{array}{l}\text { Number } \\
\text { of items }\end{array}$ & Item content & $\begin{array}{l}\text { Score } \\
\text { range }\end{array}$ \\
\hline Disease control & Psychometric & 8 & $\begin{array}{l}\text { Psychological well-being; physical well-being; speed } \\
\text { of improvement; health state stabilization; overall } \\
\text { well-being ( } 2 \text { items); protection against symptoms } \\
\text { and against surgery }\end{array}$ & $0-100$ \\
\hline Symptoms transition scale & Psychometric & 7 & $\begin{array}{l}\text { Crohn's attacks/flare-ups ( } 4 \text { items); diarrhea; } \\
\text { abdominal pain; uncontrollable need to defecate }\end{array}$ & $0-100$ \\
\hline Anal symptoms transition scale & Psychometric & 2 & Anal pain; anal leakage & $0-100$ \\
\hline Quality of life transition scale & Psychometric & 8 & $\begin{array}{l}\text { Impact on mood, on energy, on physical status, } \\
\text { on emotions in relationships, on professional life, } \\
\text { on family life, and on social life; overall impact on life }\end{array}$ & $0-100$ \\
\hline Tolerability & Composite & 3 & Information; bother; worries & $0-10$ \\
\hline Convenience & Composite & II & $\begin{array}{l}\text { Mode of administration ( } 6 \text { items): practical, } \\
\text { constraining, unpleasant, reassuring, worrisome, } \\
\text { and easy; organization constraints ( } 5 \text { items): travel, } \\
\text { costs, conservation, work, and children }\end{array}$ & $0-21$ \\
\hline $\begin{array}{l}\text { Expectation confirmation } \\
\text { toward efficacy }\end{array}$ & Single-item & I & & $0-100$ \\
\hline $\begin{array}{l}\text { Expectation confirmation } \\
\text { toward side effects }\end{array}$ & Single-item & I & & $0-100$ \\
\hline $\begin{array}{l}\text { Expectation confirmation } \\
\text { toward convenience }\end{array}$ & Single-item & I & & $0-100$ \\
\hline Satisfaction with treatment & Psychometric & 10 & $\begin{array}{l}\text { Efficacy on Crohn's attacks, on side effects, on } \\
\text { organization constraints, on mood, on energy, } \\
\text { on physical status, on emotions in relationships, } \\
\text { on family life, on professional life, and on social life }\end{array}$ & $0-100$ \\
\hline Motivation & Psychometric & 4 & $\begin{array}{l}\text { Acceptability of side effects and of constraints; } \\
\text { motivation to continue taking treatment; } \\
\text { overall evaluation }\end{array}$ & $0-100$ \\
\hline
\end{tabular}

Note: aExcluding the two items about type of treatment administration and patient's expectations about future new treatments kept outside the scoring.

score, the better the patient's experience with the treatment: ie, greater disease control, fewer symptoms, better quality of life, better tolerability and convenience, greater satisfaction, and motivation toward treatment.

To help with reading the scores of the SPACE-Q and to better explore the relationship between the treatment benefit and the treatment satisfaction perceived by the patient, a rearrangement of the dimensions was suggested by the clinicians of the advisory board. The following proposed order aimed to reflect the thinking process of the patient when evaluating a treatment: 1) perceived treatment benefits, assessed with the disease control and the three transition scale dimensions; 2) evaluation of treatment attributes, assessed with the tolerability and convenience dimensions; 3) evaluation of the treatment compared with initial expectations, assessed with the three expectation confirmation dimensions; and, finally, 4) overall patient satisfaction with their treatment and patients' motivation to pursue their treatment, assessed with the satisfaction and motivation dimensions, respectively.

\section{Psychometric validation phase}

A description of scores for each dimension of the SPACE-Q at inclusion and at week 12 is presented in detail in Table 4.

As is illustrated in Figure 1, the SPACE-Q demonstrated good clinical validity. Statistically significant differences in psychometric SPACE-Q scores were observed between groups with different degrees of disease severity, as evaluated by the Harvey-Bradshaw index. Patients with inactive disease reported higher SPACE-Q scores than patients with active or very severe disease (Figure 1). For example, the mean satisfaction with treatment score at inclusion was 60.6, 50.2, and 41.5 for patients with inactive, active, and very severe disease, respectively $(P<0.001)$. The only SPACE-Q scores for which no clear relationship was observed with the disease severity evaluated with the Harvey-Bradshaw index were the convenience, tolerability, and expectation confirmation toward convenience scores.

Correlation coefficients between SPACE-Q scores and TSQM scores ranged from low to moderate (Table 5). Low correlations were seen between scores measuring different 
Table 4 Description of Satisfaction for PAtients in Crohn's diseasE Questionnaire scores in the study at inclusion and week 12 to assess patients' satisfaction with anti-tumor necrosis factor treatment

\begin{tabular}{|c|c|c|c|c|c|c|}
\hline \multirow[t]{2}{*}{ Dimension score } & \multicolumn{3}{|c|}{ Inclusion } & \multicolumn{3}{|c|}{ Week I2 } \\
\hline & $\mathbf{N}$ & Mean (SD) & Min-max & $\mathbf{N}$ & Mean (SD) & Min-max \\
\hline $\begin{array}{l}\text { Disease control } \\
(0=\text { worse; } 100=\text { better control })\end{array}$ & 262 & $42.1(24.2)$ & $0.0-100.0$ & 155 & $64.0(22.3)$ & $4.2-100.0$ \\
\hline $\begin{array}{l}\text { Symptoms transition scale } \\
\text { ( } 0=\text { worse; } 100=\text { fewer symptoms) }\end{array}$ & 263 & $34.8(26.3)$ & $0.0-100.0$ & 153 & $56.7(26.1)$ & $0.0-100.0$ \\
\hline $\begin{array}{l}\text { Anal symptoms transition scale } \\
(0=\text { worse; } 100=\text { fewer anal symptoms })\end{array}$ & 264 & 73.4 (30.9) & $0.0-100.0$ & 154 & $76.1(27.8)$ & $0.0-100.0$ \\
\hline $\begin{array}{l}\text { Quality of life transition scale } \\
(0=\text { worse; } 100=\text { better quality of life })\end{array}$ & 261 & $49.9(20.5)$ & $0.0-100.0$ & 155 & $63.2(19.9)$ & $6.3-100.0$ \\
\hline $\begin{array}{l}\text { Tolerability } \\
(0=\text { worse; } 10=\text { better tolerability })\end{array}$ & 258 & $5.8(2.4)$ & $0.0-10.0$ & 154 & $6.3(2.2)$ & $0.0-10.0$ \\
\hline $\begin{array}{l}\text { Convenience } \\
\text { ( } 0=\text { worse; } 2 \mathrm{I}=\text { =better convenience) }\end{array}$ & 235 & $16.9(3.4)$ & $5.0-21.0$ & 142 & $17.0(3.0)$ & $3.0-21.0$ \\
\hline $\begin{array}{l}\text { Expectation confirmation toward efficacy } \\
(0=\text { worse; } 100=\text { better than expected })\end{array}$ & 257 & $33.3(26.6)$ & $0.0-100.0$ & 155 & $51.6(28.0)$ & $0.0-100.0$ \\
\hline $\begin{array}{l}\text { Expectation confirmation toward side effects } \\
(0=\text { worse; } 100=\text { better than expected })\end{array}$ & 259 & $52.7(23.7)$ & $0.0-100.0$ & 155 & $66.0(22.6)$ & $0.0-100.0$ \\
\hline $\begin{array}{l}\text { Expectation confirmation toward convenience } \\
\text { ( } 0=\text { worse; } 100=\text { better than expected) }\end{array}$ & 259 & $55.1(21.8)$ & $0.0-100.0$ & 156 & $62.3(20.8)$ & $25.0-100.0$ \\
\hline $\begin{array}{l}\text { Satisfaction with treatment } \\
(0=\text { worse; } 100=\text { greater satisfaction })\end{array}$ & 256 & $51.9(21.7)$ & $0.0-100.0$ & 155 & $65.0(18.7)$ & $8.3-100.0$ \\
\hline $\begin{array}{l}\text { Motivation } \\
\text { ( } 0=\text { worse; } 100=\text { greater motivation })\end{array}$ & 260 & $59.4(20.5)$ & $0.0-100.0$ & 156 & $73.3(18.2)$ & $14.6-100.0$ \\
\hline
\end{tabular}

Abbreviation: SD, standard deviation.

concepts (eg, SPACE-Q convenience and TSQM side effect scores, $r=0.15)$. Moderate correlations were seen between scores measuring related concepts (eg, SPACE-Q tolerability and TSQM side effect scores, $r=0.57$ ). There were no correlation coefficients $>0.70$, indicating no overlap between the SPACE-Q and TSQM scores. These results support the good concurrent validity of the SPACE-Q.

Cronbach's $\alpha$ values calculated to assess the internal consistency reliability were higher than the recommended
0.70 threshold for all psychometric dimensions but one, the anal symptoms transition scale dimension (0.52) (Table 6). This low value can be explained by the fact that anal symptoms occur only in a smaller subgroup of patients with Crohn's disease, representing a minority in the total sample. Moreover, this dimension comprises only two items. The SPACE-Q was administered at weeks 12 and 13 to patients whose PGIC responses were stable during this period $(n=32)$. Intraclass correlation coefficients were found to be higher than

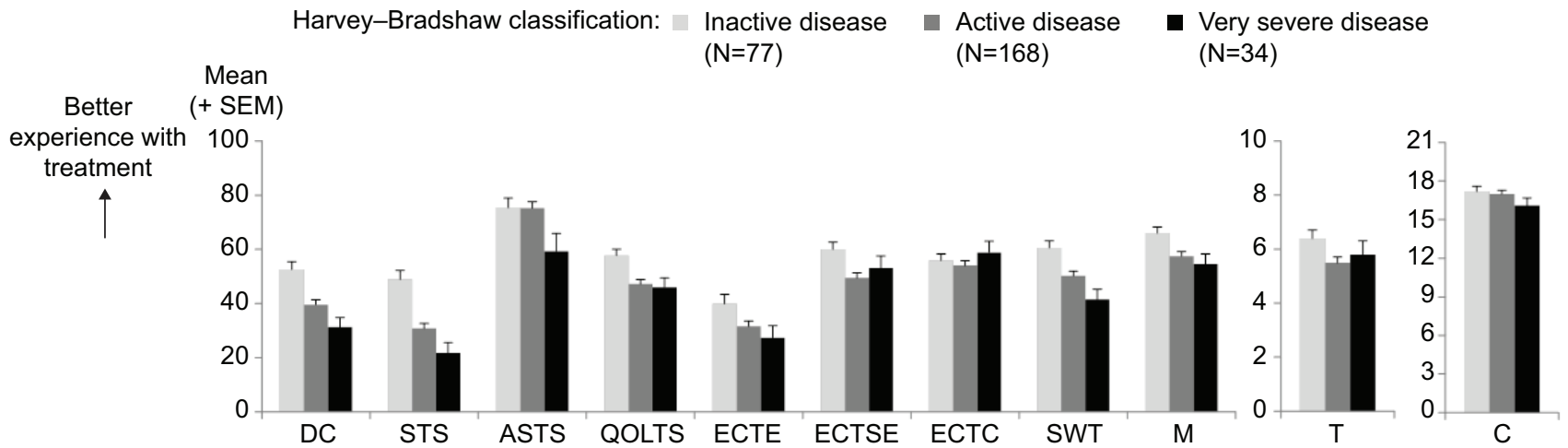

Figure I Clinical validity - comparison of SPACE-Q ${ }^{\odot}$ scores according to Harvey-Bradshaw index at inclusion. SPACE-Q scores are shown as mean (SEM).

Note: $P$-value obtained from analysis of variance.

Abbreviations: SPACE-Q ${ }^{\odot}$, Satisfaction for PAtients in Crohn's diseasE Questionnaire; SEM, standard error of the mean; DC, disease control; STS, symptoms transition scale; ASTS, anal symptoms transition scale; QOLTS, quality of life transition scale; ECTE, expectation confirmation toward efficacy; ECTSE, expectation confirmation toward side effects; ECTC, expectation confirmation toward convenience; SWT, satisfaction with treatment; M, motivation; T, tolerability; C, convenience. 
Table 5 Concurrent validity - Pearson correlation coefficients between Satisfaction for PAtients in Crohn's diseasE Questionnaire (SPACE- $\mathrm{Q}^{\odot}$ ) scores and Treatment Satisfaction Questionnaire for Medication (TSQM) scores at inclusion

\begin{tabular}{lllll}
\hline SPACE-Q & & & \\
& sSQM score & & \\
\cline { 2 - 5 } & Side effects & Effectiveness & Convenience & Global satisfaction \\
\hline Disease control & 0.15 & 0.62 & 0.22 & 0.60 \\
Symptoms transition scale & 0.10 & 0.56 & 0.23 & 0.55 \\
Anal symptoms transition scale & 0.17 & 0.16 & 0.14 & 0.17 \\
Quality of life transition scale & 0.36 & 0.47 & 0.32 & 0.54 \\
Tolerability & 0.57 & 0.11 & 0.18 & 0.17 \\
Convenience & 0.15 & 0.11 & 0.46 & 0.21 \\
Expectation confirmation toward efficacy & 0.11 & 0.58 & 0.25 & 0.59 \\
Expectation confirmation toward side effects & 0.36 & 0.22 & 0.30 & 0.35 \\
Expectation confirmation toward convenience & 0.12 & 0.10 & 0.25 & 0.23 \\
Satisfaction with treatment & 0.38 & 0.55 & 0.41 & 0.59 \\
Motivation & 0.40 & 0.55 & 0.35 & 0.65 \\
\hline
\end{tabular}

the recommended 0.70 threshold, except for the expectation confirmation toward convenience score $(r=0.62)$ (Table 6). These findings showed that both the internal consistency and test-retest reliability of the SPACE-Q were good.

Finally, statistically significant differences in changes in almost all psychometric SPACE-Q scores were observed according to PGIC. Improved patients according to PGIC reported a greater improvement in their experience with their treatment (greater changes in SPACE-Q scores) compared with stable patients (Table 7). Large effect sizes were observed for all SPACE-Q scores related to treatment efficacy (1.21-1.75) for the improved patients, while the effect sizes for the same scores were small $(<0.35)$ for stable patients. Overall, these results indicate that the SPACE-Q demonstrated good responsiveness to change over time.

\section{Discussion}

The SPACE-Q was recently developed to evaluate satisfaction with anti-TNF treatments of patients with severe Crohn's disease. ${ }^{13}$ In this multicenter, longitudinal, noninterventional study, we have shown that this questionnaire is well accepted by patients with severe Crohn's disease and is a valid, reliable, and responsive tool to assess their satisfaction with respect to the specificities of anti-TNF treatment.

Following the finalization analysis phase, four items were considered uninformative and were removed from the original 62-item pilot version of the questionnaire. One item about food problems was not considered to be of particular interest from a clinical perspective and was not found to add substantial information to any of the treatment efficacy dimensions. An item about pregnancy could only be answered by women in their childbearing years willing to have a child, which made its inclusion into the aggregated score difficult. Items about limitations to scheduled appointments and limitations on time were found to have a nonstatistically significant impact on acceptance of constraints.

The 58 retained items were grouped into eleven dimensions related to treatment benefits, convenience, tolerability,

Table 6 Internal consistency reliability - Cronbach's $\alpha$ at inclusion and week 12 and ICC between week 12 and week 13

\begin{tabular}{|c|c|c|c|c|c|c|}
\hline \multirow[t]{2}{*}{$\begin{array}{l}\text { SPACE-Q }{ }^{\odot} \text { score } \\
\text { (number of items) }\end{array}$} & \multicolumn{2}{|c|}{ Inclusion } & \multicolumn{2}{|c|}{ Week 12} & \multicolumn{2}{|c|}{$\begin{array}{l}\text { Between week I } 2 \text { and } \\
\text { week I3 }\end{array}$} \\
\hline & $\mathbf{N}$ & Cronbach's $\alpha$ & $\mathbf{N}$ & Cronbach's $\alpha$ & $\mathbf{N}$ & ICC \\
\hline Disease control (8) & 198 & 0.89 & 129 & 0.89 & 31 & 0.90 \\
\hline Symptoms transition scale (7) & 188 & 0.89 & $|3|$ & 0.88 & 32 & 0.89 \\
\hline Anal symptoms transition scale (2) & 210 & 0.52 & 136 & 0.53 & 32 & 0.89 \\
\hline Quality of life transition scale (8) & 205 & 0.93 & 132 & 0.94 & 32 & 0.89 \\
\hline Tolerability (3) & & NA & & NA & 30 & 0.83 \\
\hline Convenience (II) & & NA & & NA & 26 & 0.91 \\
\hline Expectation confirmation toward efficacy (I) & & NA & & NA & 32 & 0.82 \\
\hline Expectation confirmation toward side effects (I) & & NA & & NA & 32 & 0.71 \\
\hline Expectation confirmation toward convenience (I) & & NA & & NA & 32 & 0.62 \\
\hline Satisfaction with treatment $(10)$ & 199 & 0.93 & 128 & 0.92 & 32 & 0.84 \\
\hline Motivation (4) & 207 & 0.67 & 132 & 0.78 & 32 & 0.79 \\
\hline
\end{tabular}

Abbreviations: ICC, intraclass correlation coefficient; SPACE-Q ${ }^{\odot}$, Satisfaction for PAtients in Crohn's diseasE Questionnaire; NA, not applicable as composite or singleitem score. 
Table 7 Responsiveness - comparison of changes in SPACE-Q ${ }^{\odot}$ scores from inclusion to week 12 according to PGIC ${ }^{a}$ to assess changes in patients' satisfaction with anti-tumor necrosis factor treatment

\begin{tabular}{|c|c|c|c|c|c|c|c|}
\hline \multirow[t]{2}{*}{ SPACE-Q $^{\oplus}$ score $^{\mathrm{b}}$} & \multicolumn{3}{|c|}{ PGIC = improved $(\mathbf{N}=70)$} & \multicolumn{3}{|c|}{ PGIC $=$ no change $(N=66)$} & \multirow[t]{2}{*}{$P$-value ${ }^{c}$} \\
\hline & $\mathbf{N}$ & $\begin{array}{l}\text { Mean change } \\
\text { in score (SD) }\end{array}$ & Effect size & $\mathbf{N}$ & $\begin{array}{l}\text { Mean change } \\
\text { in score (SD) }\end{array}$ & Effect size & \\
\hline Disease control & 66 & $41.7(24.7)$ & 1.75 & 63 & $9.7(23.6)$ & 0.26 & $<0.001$ \\
\hline Symptoms transition scale & 67 & $38.8(28.1)$ & 1.50 & 64 & $9.6(24.9)$ & 0.26 & $<0.001$ \\
\hline Anal symptoms transition scale & 67 & $8.8(24.7)$ & 0.20 & 62 & $4.4(24.4)$ & 0.10 & 0.319 \\
\hline Quality of life transition scale & 69 & $24.6(23.3)$ & 1.24 & 60 & $5.7(21.8)$ & 0.17 & $<0.001$ \\
\hline Tolerability & 68 & $\mathrm{I} .0(2.4)$ & 0.45 & 61 & $0.1(2.3)$ & 0.04 & 0.026 \\
\hline Convenience & 56 & $0.2(4.5)$ & 0.09 & 50 & $0.2(3.6)$ & 0.04 & 0.988 \\
\hline Expectation confirmation toward efficacy & 66 & $39.4(35.1)$ & 1.44 & 62 & $8.1(28.9)$ & 0.12 & $<0.001$ \\
\hline Expectation confirmation toward side effects & 66 & $18.9(30.7)$ & 0.76 & 63 & $6.7(26.3)$ & 0.32 & 0.017 \\
\hline Expectation confirmation toward convenience & 68 & $10.3(33.8)$ & 0.39 & 62 & $1.2(25.8)$ & 0.16 & 0.090 \\
\hline Satisfaction with treatment & 67 & $26.8(23.9)$ & 1.21 & 58 & $4.8(19.7)$ & 0.14 & $<0.001$ \\
\hline Motivation & 68 & $23.0(25.0)$ & 1.16 & 63 & $6.1(19.1)$ & 0.26 & $<0.001$ \\
\hline
\end{tabular}

Notes: "PGIC = improved": patients who reported their condition was much or very much improved; "PGIC = no change": patients who reported no change or minimal improvement or minimal worsening. ' ${ }^{A}$ change in SPACE-Q scores $<0$ indicates a deterioration in the patients' experience with treatment; a change in SPACE- $Q$ scores $>0$ indicates an improvement in the patients' experience with treatment. 'P-value obtained from analysis of variance.

Abbreviations: SPACE-Q ${ }^{\odot}$, Satisfaction for PAtients in Crohn's diseasE Questionnaire; PGIC, patient global impression of change; SD, standard deviation.

satisfaction, and motivation. The SPACE-Q provides a comprehensive picture of the multifaceted nature of patient satisfaction with anti-TNF treatment. It covers important aspects reported by patients, such as the impact of side effects, delivery mode, and the perceived treatment benefits and tolerance. ${ }^{5}$ The SPACE-Q was developed following a rigorous methodology compatible with regulatory authorities' standard requirements for patient-reported outcome instruments. ${ }^{13,14} \mathrm{In}$ this study, we found that the final version of the SPACE-Q demonstrated good psychometric properties, including good clinical and concurrent validity, good internal consistency and test-retest reliability, and good responsiveness.

The final 58-item version of the SPACE-Q could be considered a long questionnaire. However, each item addresses a concept specifically mentioned by patients during the development phase of the questionnaire. Moreover, we found that the questionnaire was well accepted, as shown by the few missing data. Despite the length, we did not observe any fading in the completion toward the end of the questionnaire. Thus, we believe the SPACE-Q to be fully appropriate for use in clinical trials or epidemiological studies to obtain a comprehensive picture of patient satisfaction with anti-TNF treatments. Studies that focus on specific aspects of anti-TNF satisfaction versus this comprehensive picture, or specific contexts of use such as daily clinical practice, may require a shorter version of the questionnaire; obviously, this would require reconsideration of all the concepts and assessment of the psychometric performance of any shortened version of the questionnaire in a new validation study.

The advantage of the SPACE-Q compared with generic treatment satisfaction measures like the TSQM is that it is specific to Crohn's disease and to anti-TNF treatment. In addition, the SPACE-Q was developed following a robust qualitative process. Both clinicians and patients were involved to provide an accurate and complete evaluation of satisfaction in relation to Crohn's disease and anti-TNF treatment. In particular, the SPACE-Q addresses concepts that the TSQM does not cover, such as the impact on quality of life and the motivation to continue treatment, which are essential elements in the overall satisfaction picture.

The SPACE-Q was developed and validated using a population receiving either adalimumab or infliximab. None of the patients received certolizumab, a recently developed anti-TNF treatment that has shown to be effective in treating patients with severe Crohn's disease. ${ }^{23}$ (At the time the questionnaire was developed and validated, certolizumab was not approved for use in France, where the study was performed). However, the SPACE-Q should still be appropriate in this group of patients, as certolizumab shares similar qualities with other anti-TNF treatments, especially regarding its delivery mode. ${ }^{24}$

In our study, the health state of almost all patients improved or was stable between inclusion and week 12, as evaluated by the patients themselves. This can be explained by the reported effectiveness of anti-TNF treatments in patients who were refractory to conventional treatments or who switched to a new anti-TNF treatment. ${ }^{25,26}$ In this study, too few patients experienced worsening of their condition to enable responsiveness to be assessed properly for this group of patients. The ability of the questionnaire to detect worsening should be confirmed in a future study.

As previously mentioned, the questionnaire was developed and validated in a French population only, restricting 
its use in international studies. This study is currently being replicated in several other countries to confirm our findings and validate the instrument in different languages in order to enable its use in future international studies.

\section{Conclusion}

In conclusion, the SPACE-Q is a reliable, valid, and responsive tool that can be used in future clinical trials or epidemiological studies to assess treatment satisfaction of patients with severe Crohn's disease treated with anti-TNF treatments.

\section{Copyright}

The Satisfaction for PAtients in Crohn's diseasE Questionnaire $\left(\mathrm{SPACE}-\mathrm{Q}^{\odot}\right)$ is protected by copyright with all rights reserved to Abbvie France. Do not use without permission. For information on, or permission to use, SPACE-Q ${ }^{\odot}$, please contact the Mapi Research Trust at 27 Rue de la Villette, 69003 Lyon, France; telephone +33 (0) 4721365 75; email trust@mapi.fr; or website www.mapi-trust.org.

\section{Acknowledgments}

We are extremely grateful to the patients who contributed to this study and we thank all the participating investigators: Abitbol Vered, Service de Gastroentérologie, Hôpital Cochin, Paris; Allez Matthieu, Service d'Hépato-Gastroentérologie, Hôpital Saint-Louis, Paris; Bonaz Bruno and Mathieu Nicolas, Service d'Hépato-Gastroentérologie, CHU Hôpital Michallon, Grenoble; Bonnaud Guillaume, Service de Gastroentérologie, Clinique des Cèdres, Cornebarrieu; Bouhnik Yoram, Service de Gastroentérologie et Assistance Nutritive, Hôpital Beaujon, Clichy; Bourreille Arnaud and Flamant Mathurin, Service d'Hépato-Gastroentérologie IMAD, CHU Hôtel Dieu, Nantes; Cadiot Guillaume and Brixi Hedia, Service d'Hépato-Gastroentérologie, CHU Hôpital Robert Debré, Reims; Carbonnel Franck, Service d'Hépato-Gastroentérologie-Nutrition, Centre Hospitalier de Bicêtre, Le Kremlin Bicêtre; Colombel Jean-Frédéric and Nachury Maria, Hôpital Claude Huriez, Lille; Cuillerier Emmanuel, Service d'Hépato-Gastroentérologie, Centre Hospitalier Victor Jousselin, Dreux; Dupas Jean-Louis, Service d'Hépato-Gastroentérologie, CHU Amiens; Faure Patrick, Clinique Saint-Jean du Languedoc, Toulouse; Flourié Bernard and Nancey Stéphane, Service d'Hépato-Gastroentérologie, CHU Hôpital Lyon Sud, Lyon; Grimaud Jean-Charles, Service d'Hépato-Gastroentérologie, CHU Hôpital Nord, Marseille; Hagège Hervé, Centre Hospitalier Intercommunal, Créteil; Hebuterne Xavier, Service de Gastroentérologie et Nutrition, CHU Hôpital de l'Archet 2, Nice; Laharie David,
Service d'Hépato-Gastroentérologie et Nutrition, CHU Hôpital Haut-Lévêque, Pessac; Lerebours Eric and Savoye Guillaume, Service d'Hépato-Gastroentérologie et Nutrition, CHU Hôpital Charles-Nicolle, Rouen; Levy Patrick, Strasbourg; Moreau Jacques, Service de Gastroentérologie et Nutrition, CHU de Rangueil, Toulouse; Nahon Stéphane, Centre Hospitalier Intercommunal, Le Raincy Montfermeil; Peyrin-Biroulet Laurent, Service d'Hépato-Gastroentérologie, CHU Hôpital du Brabois, Nancy; Pingannaud Marie-Pierre, Marseille; Reimund Jean-Marie, Service d'Hépato-Gastroentérologie et Nutrition, CHU Caen; Roblin Xavier, Service de Gastroentérologie, CHU Saint Etienne; Tucat Gilbert, Paris; Vandromme Luc, Reims; and Veyrac Michel, Service d'Hépato-Gastroentérologie, CHU Hôpitaux Saint-Eloi, Montpellier. Jérémy Lambert (Mapi) was compensated by Abbvie for his medical writing skills.

\section{Disclosure}

Financial support for the observational study was provided by Abbvie Laboratories. JFC, PF, HH, MN, SN, GT, and LV have served as consultants for Abbvie Laboratories and have received research funding from Abbvie Laboratories. BA, FF, and $\mathrm{HG}$, employees of Mapi, and PC and ODH, employees of Orgamétrie, received financial support from Abbvie. ICT and ET are employees of Abbvie and may own Abbvie stock.

\section{References}

1. Baumgart DC. The diagnosis and treatment of Crohn's disease and ulcerative colitis. Dtsch Arztebl Int. 2009;106:123-133.

2. Cohen RD. The quality of life in patients with Crohn's disease. Aliment Pharmacol Ther. 2002;16:1603-1609.

3. Janke KH, Klump B, Gregor M, Meisner C, Haeuser W. Determinants of life satisfaction in inflammatory bowel disease. Inflamm Bowel Dis. 2005;11:272-286

4. Dignass A, Van AG, Lindsay JO, et al. The second European evidencebased consensus on the diagnosis and management of Crohn's disease: current management. J Crohns Colitis. 2010;4:28-62.

5. Allen PB, Lindsay H, Tham TC. How do patients with inflammatory bowel disease want their biological therapy administered? BMC Gastroenterol. 2010;10:1.

6. Shikiar R, Rentz AM. Satisfaction with medication: an overview of conceptual, methodologic, and regulatory issues. Value Health. 2004;7: 204-215.

7. Oliver RL. Satisfaction: A Behavioral Perspective on the Consumer. New York: McGraw-Hill; 1997.

8. Dias Barbosa C, Balp MM, Kulich K, Germain N, Rofail D. A literature review to explore the link between treatment satisfaction and adherence, compliance, and persistence. Patient Prefer Adherence. 2012;6:39-48.

9. Atkinson MJ, Sinha A, Hass SL, et al. Validation of a general measure of treatment satisfaction, the Treatment Satisfaction Questionnaire for Medication (TSQM), using a national panel study of chronic disease. Health Qual Life Outcomes. 2004;2:12.

10. Ruiz MA, Pardo A, Rejas J, Soto J, Villasante F, Aranguren JL. Development and validation of the "Treatment Satisfaction with Medicines Questionnaire" (SATMED-Q). Value Health. 2008;11:913-926. 
11. Coyne K, Joshua-Gotlib S, Kimel M, Thompson C, Lewis A, Danilewitz M. Validation of the Treatment Satisfaction Questionnaire for Crohn's Disease (TSQ-C). Dig Dis Sci. 2005;50:252-258.

12. Clark M, Colombel JF, Feagan BC, et al. American gastroenterological association consensus development conference on the use of biologics in the treatment of inflammatory bowel disease, June 21-23, 2006. Gastroenterology. 2007;133:312-339.

13. Marant C, Arnould B, Marrel A, et al. Assessing patients' satisfaction with anti-TNFalpha treatment in Crohn's disease: qualitative steps of the development of a new questionnaire. Clin Exp Gastroenterol. 2011;4:173-180.

14. US Department of Health and Human Services, Food and Drug Administration, Center for Drug Evaluation and Research, Center for Biologics Evaluation and Research, Center for Devices and Radiological Health. Guidance for Industry. Patient-Reported Outcome Measures: Use in Medical Product Development to Support Labeling Claims. Available from: http://www.fda.gov/downloads/Drugs/GuidanceCompliance RegulatoryInformation/Guidances/UCM193282.pdf. Accessed October 3, 2014.

15. Mapi Research Trust. Satisfaction of PAtients with Crohn's diseasE (SPACE) [webpage on the internet]. Available from: http://www. proqolid.org/instruments/satisfaction_of_patients_with_crohn_s_ disease_space. Accessed October 3, 2014.

16. Campbell DT, Fiske DW. Convergent and discriminant validation by the multitrait-multimethod matrix. Psychol Bull. 1959;56:81-105.

17. Chassany O, Sagnier P, Marquis P, Fullerton S, Aaronson N. Patientreported outcomes: the example of health-related quality of life: a European guidance document for the improved integration of healthrelated quality of life assessment in the drug regulatory process. Drug Inf J. 2002;36:209-238.
18. Harvey RF, Bradshaw JM. A simple index of Crohn's disease activity. Lancet. 1980;1:514.

19. Nunnally JC, Bernstein IH. Psychometric Theory. 3rd ed. New York: McGraw-Hill Inc; 1994.

20. Streiner DL. Being inconsistent about consistency: when coefficient alpha does and doesn't matter. J Pers Assess. 2003;80:217-222.

21. Guyatt GH, Deyo RA, Charlson M, Levine MN, Mitchell A. Responsiveness and validity in health status measurements: a clarification. J Clin Epidemiol. 1989;42:403-408.

22. Cohen J. Statistical Power Analysis for the Behavioral Sciences. New York: Academic Press; 1977.

23. Vavricka SR, Schoepfer AM, Bansky G, et al. Efficacy and safety of certolizumab pegol in an unselected Crohn's disease population: 26-week data of the FACTS II survey. Inflamm Bowel Dis. 2011;17: 1530-1539.

24. Schreiber S. Certolizumab pegol for the treatment of Crohn's disease. Therap Adv Gastroenterol. 2011;4:375-389.

25. Cassinotti A, Ardizzone S, Porro GB. Adalimumab for the treatment of Crohn's disease. Biologics. 2008;2:763-777.

26. Caviglia R, Boskoski I, Cicala M. Maintenance treatment with infliximab for the management of Crohn's disease in adults. Biologics 2009;3:39-49.
Patient Preference and Adherence

\section{Publish your work in this journal}

Patient Preference and Adherence is an international, peer-reviewed, open access journal that focuses on the growing importance of patient preference and adherence throughout the therapeutic continuum. Patient satisfaction, acceptability, quality of life, compliance, persistence and their role in developing new therapeutic modalities and compounds to optimize

\section{Dovepress}

clinical outcomes for existing disease states are major areas of interest for the journal. This journal has been accepted for indexing on PubMed Central. The manuscript management system is completely online and includes a very quick and fair peer-review system, which is all easy to use. Visit http://www. dovepress.com/testimonials.php to read real quotes from published authors. 